\title{
Attention deficit disorder, comorbidity, and treatment at the Hospital Psiquiátrico Infantil Dr. Juan N. Navarro, Mexico City
}

\author{
Juan C. Reséndiz-Aparicio ${ }^{1 *}$, María del P. Poza-y Díaz², Esmeralda Arriaga-Cruz², Inés A. Nogales-Imaca², \\ Dalia M. Becerra-Alcántara², Ernesto Rodríguez-Rodríguez ${ }^{1}$, and Michel Gutiérrez-Ceniceros ${ }^{1}$ \\ ${ }^{1}$ Department of Pediatric Neurology; ${ }^{2}$ Department of Child Psychiatry, Hospital Psiquiátrico Infantil Dr. Juan N. Navarro, Mexico City, Mexico
}

\begin{abstract}
Background: Attention deficit hyperactivity disorder (ADHD) is the main motive for consultation at the Hospital Psiquiátrico Infantil. Materials and methods: Prospective study analyzing patients with ADHD for 2 months. Results: Recruited 555 patients, average age 8.7 ( \pm 1.66$)$ years, $485(87.4 \%)$ males and $70(12.6 \%)$ females. The most frequent subtype was combined in 440 (79.3\%). We observed high comorbidity (68.1\%), with externalizing disorders 143 (25.8\%) patients and internalizing disorders 136 (24.5\%). Epilepsy was found in eight patients. The most commonly used medications were methylphenidate for 485 cases (87.4\%), followed by risperidone $45(8.1 \%)$, fluoxetine $32(5.8 \%)$, and without drug treatment $31(5.6 \%)$. Mood stabilizers in 102 patients (18.4\%), 32\% received more than one drug. The most frequent combinations were methylphenidate with valproate, methylphenidate with risperidone, and methylphenidate with fluoxetine. Conclusions: Males attend more frequently, and the most frequent subtype is combined. Comorbidity presented in almost $70 \%$, most predominantly with the oppositional defiant disorder. Methylphenidate is the most commonly used drug in monotherapy or in combination.
\end{abstract}

Key words: Attention deficit hyperactivity disorder. Comorbidity. Treatment. Methylphenidate.

\section{Trastorno por déficit de atención, comorbilidad y tratamiento en el Hospital Psiquiátrico Infantil Dr Juan N. Navarro, Ciudad de México}

\section{Resumen}

Antecedentes: TDAH es el principal motivo de consulta en el Hospital Psiquiátrico Infantil. Métodos: Analizamos pacientes con TDAH (DSM-5), durante dos meses. Resultados: Reclutamos 555 pacientes, edad promedio de 8.7 ( \pm 1.66$)$ años, varones 485 (87.4\%) y mujeres 70 (12.6\%). El subtipo más frecuente, combinado 440 pacientes (79.3\%). Observamos alta comorbilidad (68.1\%), los trastornos externalizados en 143 pacientes (25.8\%) y los internalizados 136 (24.5\%). Epilepsia se encontró en 8 pacientes. Medicamento más empleado metilfenidato en 485 (87.4\%), después risperidona 45 (8.1\%), fluoxetina 32 (5.8\%), sin tratamiento farmacológico 31 (5.6\%). Modulador del afecto 102 pacientes (18.4\%). El 32\% recibían más de un fármaco. Combinaciones más frecuentes metilfenidato con valproato, metilfenidato con risperidona y metilfenidato con

\section{Correspondence:}

*Juan C. Reséndiz-Aparicio

Department of Pediatric Neurology

Hospital Psiquiátrico Infantil Dr. Juan N. Navarro Date of reception: 03-10-2019

Available online: $02-03-2020$

Mexico City, Mexico

Date of reception: 03-10-2019

E-mail: jc_doc@yahoo.com

DOI: $10.24875 / R M N .19000133$

Rev Mex Neuroci. 2020;21(2):41-48

www.revmexneurociencia.com

1665-5044/@ 2019. Academia Mexicana de Neurología A.C. Published by Permanyer. This is an open access article under the CC BY-NC-ND license (http://creativecommons.org/licenses/by-nc-nd/4.0/). 
fluoxetina. Conclusiones: Los varones acuden con mayor frecuencia, el subtipo más frecuente fue combinado. La comorbilidad ocupó casi el $70 \%$, predominando el trastorno oposicionista desafiante. Metilfenidato es el fármaco de mayor uso en monoterapia o en combinación.

Palabras clave: TDAH. Comorbilidad. Tratamiento. Metilfenidato.

\section{Introduction}

Attention deficit hyperactivity disorder (ADHD) is the neurodevelopmental disorder of greatest prevalence worldwide. It is estimated to affect $5-7 \%$ of children and adolescents, and about $3 \%$ of the adult population ${ }^{1,2}$.

Polanczyk et al. reviewed 154 studies that utilized the DSM- 5 classification, like ICD-10, in patients 18 years old or younger, concluding that the global prevalence is $5 \%$. In addition, they concluded that the variations in prevalence observed in various studies could be attributed to different methods and statistics employed ${ }^{3}$.

In our setting, ADHD is considered to be the number one reason to seek attention in the psychiatric service. At the Hospital Psiquiátrico Infantil Dr. Juan N. Navarro (Children's Psychiatric Hospital Dr. Juan N. Navarro), according to statistics from 2016, the incidence reported was 1.3 new cases per day, with 476 new cases per year. This adds up to $19.1 \%$ of the global demand for said institution, as registered in the update of the clinical guides for ADHD of this institution in 2018. It is also considered to be the neurodevelopmental disorder of greatest prevalence in the pediatric neurology service $^{4}$.

In the DSM-5 (Diagnostic and Statistical Manual of Mental Disorders of the American Psychiatric Association), the prevalence is considered to be between 3 and $5 \%$. However, these numbers vary depending on the population studied, the methods used and the inclusion criteria required. Recently, a higher prevalence has been observed, reaching up to $17.1 \%^{5,6}$.

There are still no conclusive biological markers specific for ADHD. However, recent studies have revealed the participation of a group of 105 genes that show statistical significance for their association with $\mathrm{ADHD}^{7}$. The clinical variations are established in function of the symptomatic dominance of hyperactivity-impulsiveness, inattentiveness, or both ${ }^{8,9}$.

The concept of concomitant morbidity was coined in the context of chronic diseases to refer to any new clinical entity in addition to the existing one and was quickly adopted to describe the coexistence of two or more mental disorders ${ }^{9}$. Studies in child and adolescent psychopathologies have shown that concomitant morbidity frequently constitutes the rule and that there is an average of 2.5 coexisting psychiatric diagnoses, in clinics treating Mexican adolescents ${ }^{10}$.

The existence of comorbid disorders associated with ADHD constitutes an essential determiner in its evolution and prognosis ${ }^{11}$, and even in its therapeutic algorithm. Recent data indicate that over half of the people diagnosed with ADHD fulfill the criteria for one or more additional neuropsychiatric disorders ${ }^{12}$.

Epidemiological research shows high comorbidity of ADHD with externalizing disorders, such as conduct disorder (CD), oppositional defiant disorder (ODD), or both, as well as with internalizing disorders, especially major depressive disorder and anxiety disorder, as well as dysthymic disorder and bipolar disorder. There are a number of studies that emphasize the direct impact of said comorbidities on poor academic abilities, which in turn are prognostic and risk factors for internalizing disorders ${ }^{13}$.

In $C D$, there are reiterated aggressive and criminal conducts that violate the basic rights of other people or important social rules. Half of the patients with ADHD can be associated with an ODD or $\mathrm{CD}^{14}$.

Various studies agree that around $30 \%$ of the children with ADHD also have an associated affective disorder (major depression, bipolar disorder, or dysthymic disorder). Bipolar disorder is a disease that presents more commonly than had been thought in pediatrics ${ }^{15}$.

There does not seem to be a specific pattern of association between the different subtypes of anxiety disorders and the different subtypes of $A D H D^{16}$. Studies indicate that the clinical factors that better predict the chronicity of these diseases in children are: concomitant morbidity, being female, and presenting at an older age during childhood ${ }^{17}$.

Another important group of comorbidities includes learning disorders, where we find that the rates of the association are estimated to be that one in every four children with ADHD has a learning disorder ${ }^{18}$.

These symptoms are exponential in the context of a patient with ADHD and it is estimated that there is a correlation between them of $11-52 \%$, according to different studies. Together, they tend to worsen academic performance, which can affect emotional well-being and determine future professional performance ${ }^{19,20}$. 


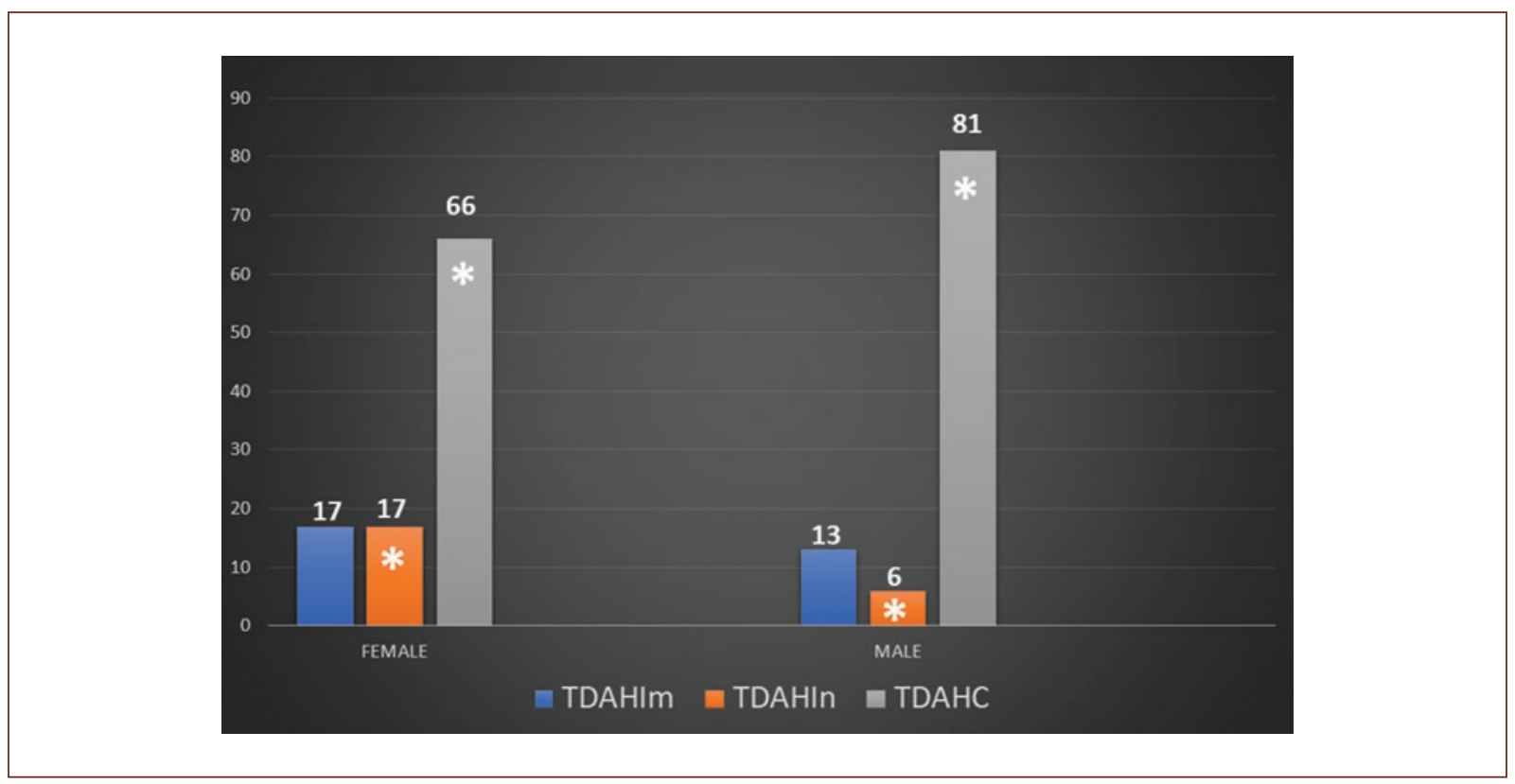

Figure 1. Distribution by gender and attention deficit hyperactivity disorder (ADHD) subtype.

*Significant difference ( $>$ >0.05). ADHDImp subtype: predominantly hyperactive-impulsive; ADHDIn subtype: predominantly inattentive; ADHDC subtype: combined.

Children with ADHD may have an increased risk of presenting epileptic seizures. It is estimated that around $15 \%$ can develop epilepsy. Diverse studies suggest that $30-40 \%$ of children with epilepsy present ADHD, in contrast to $7-9 \%$ in the general population ${ }^{21,22}$. However, epilepsy does not constitute, per se, a contraindication for treatment of ADHD, including the use of stimulants. Methylphenidate is effective for the majority of children and adolescents with ADHD and comorbid epilepsy, without an increase in the risk of seizures ${ }^{23}$.

Methylphenidate is the most commonly used medication for the treatment of ADHD, and currently, shows better tolerance since the introduction of extended-release presentations ${ }^{24}$. Atomoxetine is used as first-line therapy for ADHD and is particularly useful when the patient has comorbidity with tics, anxiety, or depressive symptoms ${ }^{25}$.

Among the atypical antipsychotics, risperidone is considered the drug of choice for the pharmacologic treatment of aggressive behavior associated with ADHD, in the case of comorbidity with $C D$, as well as with tics and Tourette syndrome ${ }^{26}$.

There are also non-neuropsychiatric comorbidities associated with ADHD, as demonstrated in a number of European studies that have described an increase in the risk of developing metabolic and cardiovascular diseases such as diabetes, obesity, and hypertension, with a subsequent risk of disease from renal failure, among others ${ }^{27}$.

The objective of this study is to identify the main comorbidities of ADHD and the treatments implemented since this condition is within the main causes of consultation in our institution. This is a report of local experience in an institution dedicated to child psychiatry and neurodevelopmental neurology.

\section{Materials and methods}

We carried out a prospective 2-month study on patients that regularly attend the clinics that treat schoolage patients at the Hospital Psiquiátrico Infantil Dr. Juan N. Navarro in Mexico City with the main diagnosis of attention deficit disorder based on DSM-5. For the purpose of this article, we abbreviate attention deficit disorder as ADHD, the predominantly inattentive subtype as ADHDIn, the predominantly hyperactive-impulsive subtype as ADHDImp, and finally, the combined or mixed subtype as ADHDC. For the analysis of results, we divided the age groups between pre-school children (4-6 years old), schoolchildren from 7 to 11 years old, pre-adolescents (12 and 13 years old), and adolescents from 14 to 18 years old. We created a database that contained age, gender, hospital registration number, attention deficit disorder subtype, 
electroencephalogram (EEG) results, family history of epilepsy, treatment used, and finally, whether there are any comorbid disorders and what these were according to DSM-5. We excluded children with clinical evidence of mental retardation, and when there was clinical doubt, we reviewed the intellectual capacity test (WISC-IV) results from the medical records. If the test was missing, it was administered before including the patient in the database. During the 2 months of the study, from Monday to Friday, the patient's data were given to the doctors in the outpatient service that attended school-age patients between 6 and 12. Later, patients ages 4 and 5 who attended these clinics were added to the database, as well as one patient who turned 13 on the day of his appointment.

\section{Results}

A total of 555 patients between the ages of 4 and 13 were recruited, with the average age being $8.7 \pm 1.6$ years, predominantly male, with 485 boys $(87.4 \%)$ and 70 females (12.6\%). The most frequent subtype of ADHD was the mixed or combined attention deficit disorder, with 440 patients, representing $79.3 \%$ of the sample and a significant predominance of males. This was followed by the predominantly hyperactive-impulsive subtype in 74 patients (13.3\%) and the inattentive subtype in 41 patients (7.4\%), for which there was a significant difference in favor of females being $17 \%$ female versus $6 \%$ male (Fig. 1). When dividing the patients by age group, we found that the preschoolers (4-6 years old) and the pre-adolescents (12-13 years old) were the minority, while the most frequent where the school-age children, that is, between 7 and 11 years old. When differentiating the population by age, gender, and subtype (Table 1), we observe that, in general, the males are being attended and diagnosed at the Hospital at a younger age with respect to the females.

In terms of clinical doubt of intellectual capacity, only five intelligence tests were required, which resulted in total scores above 95 points, normal for the patients, and without significant interscalar differences.

We found a positive medical history of epilepsy in 43 patients, representing $7.7 \%$. EEGs were not carried out for $55.8 \%$ of the patients, which is 310 children when the attending physician did not believe them necessary. For the remaining 245 patients, the results from this study are normal for 112 cases $(20.2 \%)$, while 133 patients (24\%) showed abnormal findings, only for data from slowing, unstructured background rhythms and other non-specific abnormalities, with the exception of
Table 1. Distribution by age group, gender, and ADHD subtype

\begin{tabular}{|l|c|c|}
\hline & Male & Female \\
\hline $\begin{array}{l}\text { Preschool (4-6 years) } \\
\text { ADHDImp }\end{array}$ & & \\
ADHDIn & 5 & 2 \\
ADHDC & 1 & 0 \\
Total & 27 & 7 \\
\hline School-age (7-11 years) & 33 & 9 \\
\hline ADHDImp & & \\
ADHDIn & 56 & 10 \\
ADHDC & 25 & 10 \\
Total & 348 & 36 \\
\hline Adolescents (12-13 years) & 429 & 56 \\
ADHDImp & & \\
ADHDIn \\
ADHDC \\
Total
\end{tabular}

ADHDImp subtype: predominantly hyperactive-impulsive; ADHDIn subtype: predominantly inattentive; ADHDC subtype: combined.

Table 2. Comorbidity of internalizing and externalizing disorder, according to DSM

\begin{tabular}{|l|c|c|}
\hline & $\begin{array}{c}\text { Number of } \\
\text { patients }\end{array}$ & Percentage \\
\hline Depressive dis. (grouped) & & \\
$\quad$ Mild depression & 8 & 1.4 \\
$\quad$ Moderate depression & 26 & 4.7 \\
Severe depression & 1 & 0.2 \\
Recurrent depression & 8 & 1.4 \\
Dysthymia & 14 & 2.5 \\
Total & 57 & 10.2 \\
\hline Bipolar dis. (5/7 with ADHD) & & \\
Total & 7 & 1.3 \\
\hline Anxiety dis. (grouped) & & \\
$\quad$ Anxiety dis. & 4 & 0.7 \\
Generalized anxiety dis. & 29 & 5.2 \\
\hline Mixed anxiety-depressive dis. & 15 & 2.7 \\
Unspecified anxiety dis. & 13 & 2.3 \\
\hline Obsessive compulsive dis. & 2 & 0.3 \\
\hline Post-traumatic stress & 2 & 0.3 \\
Total & 65 & 11.7 \\
\hline Mixed adjustment dis. & & \\
\hline Total & 7 & 1.3 \\
\hline Total internalizing dis. & 136 & 24.5 \\
\hline Conduct dis. & 20 & 3.6 \\
\hline Oppositional defiant dis. & 123 & 22.2 \\
\hline Total externalizing dis. & 143 & 25.8 \\
\hline
\end{tabular}

Dis.: disorder.

some patients that presented with some form of comorbid epilepsy.

A total of 378 patients (68.1\%) presented comorbidities. Of these, 312 had only one comorbidity, 51 patients had 
Table 3. Comorbidities according to DSM-5

\begin{tabular}{|c|c|c|}
\hline & Number of patients & Percentage \\
\hline $\begin{array}{l}\text { Learning dis. } \\
\text { Dyslexia } \\
\text { Dyscalculia } \\
\text { Dysgraphia } \\
\text { Mixed learning dis. } \\
\text { Total }\end{array}$ & $\begin{array}{c}21 \\
1 \\
2 \\
49 \\
73\end{array}$ & $\begin{array}{c}3.8 \\
0.2 \\
0.3 \\
8.8 \\
13.6\end{array}$ \\
\hline $\begin{array}{l}\text { Elimination dis. } \\
\text { Enuresis } \\
\text { Encopresis } \\
\text { Total }\end{array}$ & $\begin{array}{l}21 \\
13 \\
34\end{array}$ & $\begin{array}{l}3.8 \\
2.3 \\
6.1\end{array}$ \\
\hline $\begin{array}{l}\text { Inadequate family support } \\
\text { Total }\end{array}$ & 33 & 5.9 \\
\hline $\begin{array}{l}\text { Communication dis. } \\
\text { Total }\end{array}$ & 15 & 2.7 \\
\hline $\begin{array}{l}\text { Epilepsy } \\
\text { Total }\end{array}$ & 8 & 1.4 \\
\hline $\begin{array}{l}\text { Asperger syndrome } \\
\text { Total }\end{array}$ & 5 & $0-9$ \\
\hline $\begin{array}{l}\text { Separation anxiety } \\
\text { Total }\end{array}$ & 4 & 0.7 \\
\hline $\begin{array}{l}\text { Headaches } \\
\text { Total }\end{array}$ & 3 & 0.5 \\
\hline $\begin{array}{l}\text { Sexual abuse } \\
\text { Total }\end{array}$ & 2 & 0.3 \\
\hline $\begin{array}{l}\text { Chronic motor tic dis. } \\
\text { Total }\end{array}$ & 1 & 0.2 \\
\hline Total comorbidity & 378 & 68.1 \\
\hline Without comorbidity & 177 & 31.9 \\
\hline
\end{tabular}

Dis.: disorder. The number of patients with at least one comorbidity reached almost $70 \%$ of the sample population.

two, three were found in 12 patients, and three patients presented four comorbidities associated with ADHD. In this population, and in agreement with DSM-5, we found internalizing disorders in 136 patients $(24.5 \%)$ : depressive disorders in 57 (10.3\%), bipolar disorder in $7(1.3 \%)$, anxiety disorder $65(11.7 \%)$, and adjustment disorders with mixed anxiety-depression in $3(1.3 \%)$ (Table 2). Comorbid externalizing disorders expressed as CDs found in 20 individuals $(3.6 \%)$ and ODD in $123(22.2 \%)$, representing $25.8 \%$ (143), affected patients.

Other frequent comorbid disorders were learning disorders found in a total of 73 patients (13.6\%), elimination disorders in $34(6.1 \%)$, and communication disorders in 15 (2.7\%). The remaining comorbidities are shown in table 3 . We observed that only eight patients, representing $1.4 \%$ of the sample, were found to have
Table 4. Pharmacological treatment used for ADHD management

\begin{tabular}{|l|c|c|}
\hline Medication* $^{*}$ & Number of patients & Percentage \\
\hline Methylphenidate & 485 & 87.4 \\
\hline Risperidone & 45 & 8.1 \\
\hline Fluoxetine & 32 & 5.8 \\
\hline Sertraline & 24 & 4.3 \\
\hline Atomoxetine & 22 & 4.0 \\
\hline Valproate & 6 & 1.1 \\
\hline Imipramine & 5 & 0.9 \\
\hline Paroxetine & 1 & 0.2 \\
\hline Haloperidol & 1 & 0.2 \\
\hline Imipramine & 1 & 0.2 \\
\hline No treatment & 31 & 5.6 \\
\hline
\end{tabular}

*Some patients took more than one of these medications.

Table 5. Antiepileptic drugs used as mood or impulse stabilizers

\begin{tabular}{|l|c|}
\hline Medication & Number of patients \\
\hline Valproate & 66 \\
\hline Carbamazepine & 19 \\
\hline Oxcarbazepine & 4 \\
\hline Topiramate & 2 \\
\hline Lamotrigine & 1 \\
\hline Levetiracetam & 1 \\
\hline Phenytoin & 1 \\
\hline Total & $102(18.4 \%)$ \\
\hline
\end{tabular}

comorbid epilepsy with ADHD, of which seven were diagnosed before 4 years of age. Etiology was unknown in four cases and was structural in four cases. Focal epilepsy was found in six of the eight patients, three initiating in the frontal lobe and three in the temporal lobe.

An interesting finding was that five of the seven patients presenting bipolar disorder where of the ADHDImp subtype (hyperactive-impulsive).

The medications used were justified based on the results obtained from the comorbidity detected in these patients with attention deficit disorder. The most common medication employed was methylphenidate, in 485 patients $(87.4 \%)$, followed by risperidone for 
Table 6. Drug combinations: breakdown of combination therapy

\begin{tabular}{|l|c|c|}
\hline Medication & Patients & Percentage \\
\hline Two drugs & 161 & 29 \\
\hline Three drugs & 17 & 32 \\
\hline Total & 178 & 6.7 \\
\hline MPH + VPA & 37 & 5.0 \\
\hline MPH + RIS & 28 & 4.7 \\
\hline MPH + FLX & 26 & 3.8 \\
\hline MPH + SER & 21 & 3.2 \\
\hline MPH + CBZ & 18 & 2.9 \\
\hline RIS + VPA & 16 & 0.7 \\
\hline MPH + OXC & 4 & 0.5 \\
\hline MPH + IMI & 3 & 0.4 \\
\hline ATX + VPA & 2 & 0.4 \\
\hline ATX + RIS & 2 & 0.2 \\
\hline MPH + LTG & 1 & 0.2 \\
\hline MPH + LEV & 1 & 0.2 \\
\hline MPH + PRX & 1 & 0.2 \\
\hline MPH + ATX & 1 & 3 \\
\hline
\end{tabular}

MPH: methylphenidate; VPA: valproate; RIS: risperidone; FLX: fluoxetine; SER: sertraline; CBZ: carbamazepine; OXC: oxcarbazepine; IMI: imipramine; ATX: atomoxetine; LTG: lamotrigine; LEV: levetiracetam; PRX: paroxetine.

Table 7. Combination of three drugs

\begin{tabular}{|l|c|c|}
\hline Medication & Number of patients & Percentage \\
\hline MPH + VPA + RIS & 7 & 1.3 \\
\hline MPH + RIS + FLX & 2 & 0.4 \\
\hline RIS + VPA + ATX & 2 & 0.4 \\
\hline MPH + RIS + TPM & 2 & 0.4 \\
\hline ATX + FLX + VPA & 1 & 0.2 \\
\hline MPH + VPA + SER & 1 & 0.2 \\
\hline MPH + RIS + CBZ & 1 & 0.2 \\
\hline MPH + FLX + PHT & 1 & 0.2 \\
\hline
\end{tabular}

MPH: methylphenidate; VPA: valproate; RIS: risperidone; FLX: fluoxetine; ATX: atomoxetine; TPM: topiramate; SER: sertraline; CBZ: carbamazepine; PHT: phenytoin.

45 (8.1\%), fluoxetine for 32 (5.8\%), sertraline 24 (4.3\%), and atomoxetine $22(4 \%)$, (Table 4), while 31 patients did not receive any pharmacologic treatment, representing
$5.6 \%$ of the population studied. Antiepileptic drugs were used as a mood or impulse modulators in 102 patients (18.4\%), valproate being the most common, as shown in table 5.

A total of 178 patients (32\%) received more than one medication. A combination of two drugs was observed in 161 children $(29 \%)$ and the use of three drugs in $17(3 \%)$ cases. The three most frequent combinations were methylphenidate with valproate, methylphenidate with risperidone, and methylphenidate with fluoxetine, followed by other combinations, as shown in tables 6 and 7. Most (6 of 8 ) of the patients diagnosed with epilepsy and ADHD were treated with valproate and methylphenidate.

The most common association found was between ADHD and ODD (123 patients). The subtypes of attention deficit disorder in this group were ADHDImp in 14, ADHDIn in 2, and ADHDC in 107 patients. Most were treated with a combination of methylphenidate and risperidone or valproate.

\section{Conclusions}

Our institution receives a patient population of ADHD that is predominantly male. This is not surprising since, in general, it is well known that childhood psychopathologies are more frequent in this gender, especially when considering school-age patients, which were the focus of this study. Based on the DSM- 5 criteria for subtype classification, we observed that almost $80 \%$ of these patients fulfilled the requirements for both inattentiveness and hyperactivity, thus being included in the combined or mixed subtype of ADHD. The literature indicates that the predominantly hyperactive-impulsive is more frequent in males, although we did not find a significant difference for this group. However, we did find a significant prevalence of the predominantly inattentive subtype for females, data that is consistent with the literature.

We consider that the EEG should not be used routinely, although we found unspecific abnormalities more frequently in patients with more comorbidities. This should be studied further to determine whether there is a real association. We consider that the EEG is not useful as a diagnostic, prognostic, or treatment factor, nor for pharmacologic decisions, as has been determined for other childhood psychiatric disorders ${ }^{28}$.

Without a doubt, comorbidity in the patient with ADHD is a general rule, as evidenced in our study, since we found that $70 \%$ of the patients had at least one comorbidity and could present up to four comorbidities associated with ADHD. As expected, for patients with 
a greater number of comorbidities, the treatment costs are increased ${ }^{29}$. Externalizing disorders were most frequently associated with ADHD, mainly represented by ODD, for which there is a genetic component but which becomes more evident when there is improper family management. Thus, it is difficult to establish what percentage of the symptoms correspond to genetic makeup and what part corresponds to family management or dynamics. However, it is known that these patients have more severe symptoms, greater social dysfunction, and a more deteriorated quality of life ${ }^{30}$. The comorbidities with internalizing disorders made up a quarter of the associations with ADHD, and the educational learning disorders presented in more than $13 \%$ of the population, which, added to the attention problem causes educational failure for these children. A vicious circle is frequently found in these cases, since when a child presents with ADHD and learning disabilities there is an educational failure which leads to frustration and could, on the one hand, lead to anxiety or mood problems or, on the other hand, to behavioral problems. The important part is to help them break this circle and convert it into a virtuous circle.

Although there is a study, cited in a number of publication, on a group of patients in Iceland ${ }^{31}$, where the authors concluded that ADHD is associated with a greater risk of unprovoked seizures and must be considered as a risk factor for epilepsy, we did not find such a risk. Our study showed that the frequency of epilepsy in children with ADHD without an intellectual disability was similar to that of the general population in our country ${ }^{32}$. Thus, we consider that ADHD is not always a risk factor to present epilepsy. The type of epilepsy, the etiology, and the pharmacological management of this group of patients with ADHD and epilepsy were similar to that for patients with epilepsy and without ADHD in this age group.

The most used medication in our institution is methylphenidate, a first-line treatment for the treatment of ADHD in the Mexican algorithms and around the world. It is the drug of choice at our hospital due to the high rate of effectiveness, availability, and experience in its use. Another of the drugs, used as second-line treatment in various algorithms, is atomoxetine; however, this drug was used with lower frequency since the cost of the medication in our country was a factor, in some cases. Risperidone was used for an important number of cases for comorbidity management, especially to modulate impulsive and aggressive behavior, frequently observed in ODD, which predominated in our population. Selective serotonin reuptake inhibitors are used to treat comorbidities with mood disorders and anxiety which, as previously stated, were frequently associated with ADHD.

When analyzing the large numbers of associated comorbidities, we can understand the great amount of medications used. We have to consider that this hospital is a high specialty facility that concentrates these cases; thus, our patient sample is from a population with treatment difficulties. Ideally, every patient with ADHD should be approached in a multidisciplinary manner with the involvement of parents, teachers, psychologists, therapists, family counselors, social workers, and even society. In the case of requiring pharmacological management, this must be started with a single drug and only use a second when required due to the comorbidity and when the patient does not respond adequately.

An interesting observation was that, of the seven patients with comorbid bipolar disorder, five presented the hyperactive-impulsive subtype. This leads us to question whether there may be a superposition of symptoms in these patients, remembering that we have an obligation to detect the possibility of comorbidity in these cases or to carry out a differential diagnosis between the two entities since children with bipolar disorder are frequently rapid cyclers with high levels of irritability and have a chronic clinical evolution ${ }^{33}$.

\section{Study limitations}

The results found are similar to those already reported in the world literature; however, they are of institutional relevance since they provide a situational diagnosis to establish diagnostic guides for our target population. A cross-sectional study will be considered in the future.

\section{Funding}

The present investigation has not received any specific scholarship from the public, commercial, or non-profit agencies.

\section{Conflicts of interest}

None.

\section{Ethical disclosures}

Protection of human and animal subjects. The authors declare that no experiments were performed on humans or animals for this study. 
Confidentiality of data. The authors declare that no patient data appear in this article.

Right to privacy and informed consent. The authors declare that no patient data appear in this article.

\section{References}

1. NICE. Clinical Guide 72, Attention Déficit Hyperactivity Disorder: diagnosis and Management of ADHD in Children, Young People and Adults, London, England; 2018.

2. Taylor $\mathrm{E}$, Chadwick $\mathrm{O}$. Hyperactivity and conduct problems as risk factors for adolescent development. J Am Acad Child Adolesc Psychiatry. 1996;35:1213-26.

3. Polanczyk G, de Lima MS, Horta BL, Biederman J, Rohde LA. The worldwide prevalence of ADHD: a systematic review and metaregression analysis. Am J Psychiatry. 2007;164:942-8.

4. Pascual-Castroviejo I. Enfermedad comórbida del síndrome de déficit de atención con hiperactividad. Rev Neurol. 2002;35:11-7.

5. Pineda DA, Lopera F. Confirmación de la elevada prevalencia del trastorno de déficit de atención en la comunidad Colombiana. Rev Neurol. 2001;32:217-22.

6. American Psychiatric Publishing. Diagnostic and Statistical Manual of Mental Disorders. Philadelphia PA: American Psychiatric Publishing; 2013.

7. Hayman V. Genetic insights into ADHD biology. Front Psychiatry 2018;9:251.

8. De la Osa-Langreo A. Psicofarmacología de los trastornos comórbidos asociados al trastorno por déficit de atención/hiperactividad. Rev Neurol. 2007;44:31-5

9. Ulloa RE. Comorbilidad en psiquiatría infantil. In: Gutierrez JR, editor. Planificaciòn Terapeútica de Los Trastornos Psiquiátricos del Niño y del Adolescente. Madrid: Litofinter Press; 2000.

10. De la Peña F. Prevalencia, severidad del padecimiento y funcionamiento psicosocial. Salud Mental. 2009;22:88-92.

11. Roselló B. Patrones de comorbilidad en los distintos subtipos de niños con trastornos por déficit de atención con hiperactividad. Rev Neurol Clin. 2000;1:181-92.

12. Klassen AF, Millar A, Fine S. Health-related quality of life in children and adolescents who have a diagnosis of attention-deficit/hyperactivity disorder. Pediatrics. 2004;114:542-7.

13. Wijetunge GS. Prevalence of comorbidities in children with attention deficit and hyperactivity disorder at Lady Ridgeway hospital for children. Sri Lanka Child Health. 2015;44:77-81.

14. Mannuzza S, Klein RG, Abikoff $H$, Moulton JL $3^{\text {rd }}$. Significance of childhood conduct problems to later development of conduct disorder among children with ADHD: a prospective follow-up study. J Abnorm Child Psychol. 2004;32:565-73

15. Biederman J, Faraone SV. Evidence of familial association between attention deficit disorder and major affective disorders. Arch Gen Psychiatry. 1991;48:633-42.
16. Artigas-Pallares J. Comorbilidad en el trastorno por déficit de atención con hiperactividad. Rev Neurol. 2003;36:68-78

17. Biederman J, Faraone SV, Mick E, Williamson S, Wilens TE, Spencer TJ, et al. Clinical correlates of ADHD in females: findings from a large group of girls ascertained from pediatric and psychiatric referral sources. J Am Acad Child Adolesc Psychiatry. 1999;38:966-75.

18. Miranda-Casas A, Alba AM. Dificultades en el aprendizaje de matemáticas en niños con trastorno por déficit de atención e hiperactividad. Rev Neurol. 2006;42:163-70.

19. Fried R, Petty C, Faraone SV, Hyder LL, Day H, Biederman J. Is ADHD a risk factor for high school dropout? A controlled study. J Atten Disord. 2016;20:383-9.

20. Sexton CC, Gelhorn HL, Bell JA, Classi PM. The co-occurrence of reading disorder and ADHD: epidemiology, treatment, psychosocial impact, and economic burden. J Learn Disabil. 2012;45:538-64.

21. Dunn DW, Kronenberger WG. Childhood epilepsy, attention problems, and ADHD: review and practical considerations. Semin Pediatr Neurol. 2005;12:222-8.

22. Abramowitz A. epilepsy Foundation; 2018. Available from: https://www. epilepsy.com/learn/challenges-epilepsy/moods-and-behavior/ mood-and-behavior-101/epilepsy-and-adhd.

23. Verrotti A, Moavero R, Panzarino G, Di Paolantonio C, Rizzo R, Curatolo $P$. The challenge of pharmacotherapy in children and adolescents with epilepsy-ADHD comorbidity. Clin Drug Investig. 2018;38:1-8.

24. American Academy of Pediatrics. Subcommittee on Attention-Deficit/ Hyperactivity Disorder and Committee on Quality Improvement. Clinical practice guideline: treatment of the school-aged child with attention-deficit/hyperactivity disorder. Pediatrics. 2001;108:1033-44

25. Michelson D, Allen AJ, Busner J, Casat C, Dunn D, Kratochvil C, et al Once-daily atomoxetine treatment for children and adolescents with attention deficit hyperactivity disorder: a randomized, placebo-controlled study. Am J Psychiatry. 2002;159:1896-901

26. Velásquez-Tirado JD, Peña JA. Evidencia actual sobre la atomoxetina Alternativa terapeútica para el trastorno por déficit de atención e hiperactividad. Rev Neurol 2005;41:493-500.

27. Akmatov MK, Ermakova T, Bätzing J. Psychiatric and nonpsychiatric comorbidities among children with ADHD: an exploratory analysis of nationwide claims data in Germany. J Atten Disord. 2019;1:1-11.

28. Reséndiz JC, Coiscou NR. Actividad epileptiforme en trastornos psiquiátricos infantiles. Rev Neurol. 2008:46:660-3.

29. Burd L, Klug MG, Coumbe MJ, Kerbeshian J. The attention-deficit hyperactivity disorder paradox: 2 Phenotypic variability in prevalence and cost of comorbidity. J Child Neurol. 2003;18:653-60.

30. Kuhne M, Schachar R. Impact of comorbid oppositional or conduct problems on attention deficit hyperactivity disorder. J Am Acad Child Adolesc Psychiatry. 1997;36:1715-25.

31. Hesdorffer DC, Ludvigsson P, Olafsson E, Gudmundsson G, Kjartansson O, Hauser WA. ADHD as a risk factor for incident unprovoked seizures and epilepsy in children. Arch Gen Psychiatry. 2004; 61:731-6.

32. Rubio F, Reséndiz JC. Programa Prioritario de Epilepsia, Epilepsia; 2016.

33. Mick E, Biederman J, Faraone SV, Murray K, Wozniak J. Defining a developmental subtype of bipolar disorder in a sample of nonreferred adults by age at onset. J Child Adolesc Psychopharmacol. 2003;13: 453-62. 